\title{
Treating binge eating and food addiction symptoms with low-carbohydrate Ketogenic diets: a case series
}

\author{
Matthew Carmen ${ }^{1}$, Debra Lynn Safer ${ }^{2}$, Laura R. Saslow ${ }^{1}$, Tro Kalayjian ${ }^{3}$, Ashley E. Masonn ${ }^{4}$ Eric C. Westman ${ }^{5}$ and \\ Shebani Sethi Dalai ${ }^{2^{*}}$ (D)
}

\begin{abstract}
Background: Many patients with obesity and comorbid binge eating symptoms present with the desire to lose weight. Although some studies suggest that dietary restriction can exacerbate binge eating, others show dietary restriction is associated with significant reductions in binge eating. The effect of a particular type of dieting on binge eating, the ketogenic diet (a high fat, moderate protein, very low carbohydrate diet), is not known.
\end{abstract}

Case presentations: We report on the feasibility of a low-carbohydrate ketogenic diet initiated by three patients (age 54,34, and 63) with obesity (average BMl $43.5 \mathrm{~kg} / \mathrm{m}^{2}$ ) with comorbid binge eating and food addiction symptoms. All patients tolerated following the ketogenic diet (macronutrient proportion 10\% carbohydrate, 30\% protein, and 60\% fat; at least $5040 \mathrm{~kJ}$ ) for the prescribed period (e.g., 6-7 months) and none reported any major adverse effects. Patients reported significant reductions in binge eating episodes and food addiction symptoms including cravings and lack of control as measured by the Binge-Eating Scale, Yale Food Addiction Scale, or YaleBrown Obsessive-Compulsive Scale modified for Binge Eating, depending on the case. Additionally, the patients lost a range of $10-24 \%$ of their body weight. Participants reported maintenance of treatment gains (with respect to weight, binge eating, and food addiction symptoms) to date of up to 9-17 months after initiation and continued adherence to diet.

Conclusions: Although the absence of control cases precludes conclusions regarding the specific role of ketogenic diets versus other forms of dietary restriction, this is the first report to demonstrate the feasibility of prescribing a ketogenic diet for patients with obesity who report binge eating and food addiction symptoms. Further research should seek to reproduce the observed effects in controlled trials as well as to explore potential etiologies.

Keywords: Binge eating, Food addiction symptoms, Obesity, Ketogenic diet, Dietary restriction

\section{Background}

Dietary restriction in individuals with obesity who report binge eating and wish to lose weight is associated with mixed outcomes [1-3]. These inconsistencies are partly as a result of a lack of consensus regarding definitions of dietary restriction as well as diagnostic differences among study populations. For example, although dietary restriction may play a causal role in the development and maintenance of disordered eating in bulimia nervosa

\footnotetext{
* Correspondence: shebanis@stanford.edu

${ }^{2}$ Department of Psychiatry and Behavioral Sciences, Stanford University School of Medicine, 401 Quarry Road, Stanford, CA 94305 - 5723, USA Full list of author information is available at the end of the article
}

[4], studies specifically examining the effects of strict dieting in binge eating disorder (BED) have reported significant reductions and even remission of binge eating [5-8]. Re-introduction of normal dietary patterns is accompanied by an increase in binge eating, however the severity does not reach pre-treatment levels and many patients no longer meet criteria for $\operatorname{BED}[5,7,8]$. According to the DSM-5, the key diagnostic features of BED include recurrent and persistent episodes of binge eating, marked distress regarding binge eating, absence of regular compensatory behaviors, and binge eating episodes associated with a variety of physical and psychological symptoms [9]. 
Often seen co-morbid with BED are food addiction symptoms of cravings and lack of control. Although food addiction is a controversial construct, the most widely used tool for assessing self-reported addictive symptoms in relation to food is the Yale Food Addiction Scale (YFAS) - which was developed by modeling the DSM-IV criteria for substance abuse [10]. Food addiction symptoms have been described as an addictive response to foods such as sweets and starches. These symptoms include much time spent obtaining food, feelings of withdrawal when off food, continued use despite knowledge of adverse consequences, important activities reduced or given up, repeated unsuccessful attempts to quit, and taken in larger quantities or longer periods than intended [11]. The prevalence of food addiction symptoms within individuals with obesity, using YFAS criteria, ranges from 15 to $20 \%$ [12-14] with rates up to $42 \%$ among candidates for bariatric surgery $[15,16]$. While the extent of overlap between food addiction and BED is unclear, the subset of binge eaters with food addiction represent a more impaired group [17]. Higher levels of binge frequency have been associated with higher scores on the YFAS with severe food addiction identified as a score of at least a 6 [18]. However, there are currently no studies that estimate Food Addiction prevalence or incidence separate of the obese condition. There are also no studies validating consistent food addiction diagnostic criteria, and how these should differ from Binge Eating Disorder diagnostic criteria. The impact of dietary restriction among patients who report greater food addiction symptoms has not been clearly established, however a study has shown in a general population an increase in food cravings in restrained eaters compared to unrestrained eaters of specific foods, such as chocolate [19].

Ketogenic diets are high-fat, low-carbohydrate, moderate-protein dietary patterns in which the body's principal energy source is fat. This falls into an approximate range of $60 \%$ fat, $10 \%$ carbohydrates, and 30\% protein. Typical energy intake per day on a ketogenic diet is at least $5040 \mathrm{~kJ}$. If individuals adhere to this dietary pattern, nutritional ketosis results, which can be defined by sustaining blood beta-hydroxybuterate levels between .5 $\mathrm{mmol} / \mathrm{L}$ and $3 \mathrm{mmol} / \mathrm{L}$ [20]. Sustained nutritional ketosis induces a series of physiological changes involving appetite suppression, lower hunger, greater satiety, greater rates of lipolysis, reduction of lipogenesis and increased metabolic costs of gluconeogenesis and thermic effect of proteins [21]. Studies demonstrating ketone-induced appetite suppression and enhanced satiety provide a theoretical basis for prescribing a ketogenic diet for individuals with obesity who report binge eating and food addiction symptoms [22]. Such patients often endorse an inability to withstand increased levels of hunger, disturbances of satiety (e.g., "never feeling full"), food cravings, and urges to binge eat, and cite these experiences as preventing them from achieving weight loss.

Hence, we report the findings of prescribing a ketogenic diet to three patients with obesity who endorsed binge eating, food addiction symptoms upon symptom presentation and reported a desire to lose weight and improve metabolic health. Selection of these patients by the authors was not based on amount of weight lost, but on endorsement of specific initial symptom presentation of binge eating or food addiction symptoms and comorbid with the disease of obesity. Thus, these are the 3 cases reported. It was thought by the clinicians that the patients were suitable to try this approach given the treatment resistance and metabolic abnormalities the patient faced.

After describing the cases and their associated outcomes, we briefly reviewed the literature to explore possible biological mechanisms that may explain these outcomes. See Table 1 for demographic data of each patient.

\section{Case presentations: case 1}

\section{Baseline interview}

A 54-year-old, African American, college-educated postmenopausal female presented with obesity and selfreported binge eating and food addiction symptoms. She reported a history of sporadic attempts to lose weight with exercise, using over-the-counter weight loss pills, and attempting diet programs such as Weight Watchers. She reported that despite these efforts, her binge eating had only worsened. Her binge frequency was 1-3 times daily with estimated $14+$ times per week consistently over years. She believes that this contributed to her recurrent depression and history of suicide attempts.

She denied any current use of illicit substances but did report a history of addiction to cocaine and nicotine during her thirties, which she overcame with the help of Narcotics Anonymous. Other notable history included excoriation disorder (chronic skin-picking). Past treatment included bupropion and cognitive behavioral therapy (CBT) for clinical depression, which put her in remission for several years. She did not endorse current suicidal ideation or a history of sexual trauma or physical abuse. She reported family history of illicit substance use, obesity, type 2 diabetes mellitus, Alzheimer's disease, hyperlipidemia, and hypertension.

Table 1 Demographic data

\begin{tabular}{lllll}
\hline Case & Age & Gender & Race & Education \\
\hline 1 & 54 & $\mathrm{~F}$ & African American & College \\
2 & 34 & $\mathrm{M}$ & Caucasian & College \\
3 & 62 & $\mathrm{~F}$ & Caucasian & College \\
\hline
\end{tabular}




\section{Baseline testing}

See Table 2 for baseline weight and BMI. Her depression score on the Patient Health Questionnaire (PHQ-9) was 20 out of 27, indicating severe depression. She also had severe binge eating symptoms meeting DSM-5 criteria for binge eating disorder (BED), with a Binge-Eating Scale (BE) score of 35 out of 46 [23, 24]. She reported severe obsessive-compulsive symptoms regarding food, with a Yale-Brown Obsessive-Compulsive Scale modified for Binge Eating (YBOC-BE) score of 39 out of 40 [25]. She reported severe food addiction symptoms with a Yale Food Addiction Scale (YFAS) score of 10 out of 12 [10].

\section{Prescribed protocol}

Patient was seen by Dr. Sethi Dalai (a psychiatrist and obesity medicine physician) and by Dr. Eric Westman in his outpatient Duke Lifestyle Medicine Clinic (an internist and obesity medicine physician). The patient was carefully taught to follow a ketogenic diet, with carbohydrates as the only restriction to $20 \mathrm{~g}$ a day. We instructed the patient to eat whole foods, not processed, including meat and eggs, $4 \mathrm{oz}$ of hard cheese, 2 cups of assorted salad vegetables, and 1 cup of non-starchy low-carbohydrate vegetables per day. A list of vegetables, salad, and protein food options were provided. We instructed the patient to not count calories and to eat these foods until full then stop. We informed the patient that during the first few weeks (keto-adaptation phase) she might experience side effects including headache, fatigue, constipation and other symptoms associated with weight loss as her body adapted from metabolizing carbohydrates to metabolizing fats (ketosis). Binge eating was measured by clinical interview and the YFAS, YBOC-BE/BES scales were completed in clinic by paper and pen. Vitals were taken by nursing staff. Patient was seen regularly at follow-up visits every 2 weeks and asked to complete dietary recall questionnaires and track the number of carbohydrates per day. She reported adhering to an average of 20-30 g per day. After 2 months, her interval for follow up was monthly, and after month 6 , was every 3-6 months as needed.

Table 2 The effects across time of a ketogenic diet on binge eating, depression, food addiction symptoms and weight

\begin{tabular}{|c|c|c|c|c|c|}
\hline Variable & Cases & Baseline & Change after 6-7 months & Change after $9-13$ months & Change after 17 months \\
\hline \multirow{3}{*}{$\begin{array}{l}\text { Patient Health Questionnaire-9 } \\
\text { (depression subscale score) }\end{array}$} & Case 1 & 20 & -19 & & \\
\hline & Case 2 & - & - & & \\
\hline & Case 3 & - & - & & \\
\hline \multirow[t]{3}{*}{ Binge-Eating Scale } & Case 1 & 35 & -31 & & \\
\hline & Case 2 & - & - & & \\
\hline & Case 3 & - & - & & \\
\hline \multirow{3}{*}{$\begin{array}{l}\text { Yale-Brown Obsessive-Compulsive } \\
\text { Scale (modified for Binge Eating) }\end{array}$} & Case 1 & 39 & -37 & & \\
\hline & Case 2 & - & - & & \\
\hline & Case 3 & - & - & & \\
\hline \multirow[t]{3}{*}{$\begin{array}{l}\text { Reported Binge Eating Episodes } \\
\text { and Frequency }\end{array}$} & Case 1 & $\begin{array}{l}1-3 \text { times daily; } \\
14 \text { times per week }\end{array}$ & -14 weekly & -14 weekly & -14 weekly \\
\hline & Case 2 & $\begin{array}{l}1-2 \text { times daily; } 8-11 \\
\text { times per week }\end{array}$ & -8 to -11 weekly & -8 to -11 weekly & -8 to -11 weekly \\
\hline & Case 3 & $\begin{array}{l}1-2 \text { times daily; } 8-10 \\
\text { times per week }\end{array}$ & -8 to -10 weekly & -7 to -9 weekly & -8 to -11 weekly \\
\hline \multirow[t]{3}{*}{ Yale Food Addiction Scale } & Case 1 & 10 & -9 & & \\
\hline & Case 2 & 7 & -6 & & \\
\hline & Case 3 & 6 & & -4 & \\
\hline \multirow[t]{3}{*}{ Weight (kg) } & Case 1 & 115.7 & -17.0 & -26.3 & -28.2 \\
\hline & Case 2 & 145.2 & -20.4 & -19.1 & \\
\hline & Case 3 & 110.2 & -10.0 & -10.9 & \\
\hline \multirow[t]{3}{*}{ Weight (\% weight change) } & Case 1 & & -14.7 & -22.7 & -24.4 \\
\hline & Case 2 & & -14.0 & -13.2 & \\
\hline & Case 3 & & -9.1 & -9.9 & \\
\hline \multirow[t]{3}{*}{ BMI $\left(\mathrm{kg} / \mathrm{m}^{2}\right)$} & Case 1 & 43.1 & -4.6 & -9.1 & -10.0 \\
\hline & Case 2 & 47.1 & -6.8 & -6.0 & \\
\hline & Case 3 & 40.4 & -3.8 & -4.0 & \\
\hline
\end{tabular}




\section{Patient outcome}

After 6 months of following the ketogenic diet without any major adverse effects (she did endorse keto adaptation symptoms of temporary headache and fatigue in the first week, which then resolved In the second week), the patient reported that she was no longer binge eating (BES score reduced to 4 of 46). She experienced several other improvements as well, including a cessation of excoriation symptoms (picking and scratching at skin and fingernails), a feeling of empowerment, and greater control of her eating behaviors. She reported continued obsessive thoughts about food, but she felt more able to resist them (YBOC-BE score reduced to 2 of 40; YFAS score reduced to 1 of 12). In addition, she evidenced improvement in psychological functioning, including a reduction in her depressive symptoms (PHQ-9 score reduced to 1 of 27). After 6 months on the ketogenic diet, she lost $18.1 \mathrm{~kg}$, resulting in a $7.7 \mathrm{~kg} / \mathrm{m}^{2}$ reduction in BMI from $43.9 \mathrm{~kg} / \mathrm{m}^{2}$ (morbid obesity, class 3 ) to 36.2 $\mathrm{kg} / \mathrm{m}^{2}$ (obesity, class 2). At her last follow-up appointment (12 months from the initiation of the diet) she reported that she was continuing to follow the diet and had maintained her weight loss. She reported not having difficulties with adhering to the diet.

\section{Case presentations: case 2}

\section{Baseline interview}

A 34-year-old, Caucasian, college-educated male presented with obesity and self-reported history of binge eating disorder and food addiction symptoms. The patient described a lifelong history of obesity that progressively worsened throughout his teenage years and young adulthood. He also developed hyperlipidemia and obstructive sleep apnea. He described a complete lack of control over his eating, including eating in the absence of hunger and significant guilt after binge episodes. Reported binge frequency was 1-2 times per day with estimated 8-11 times per week. In particular, he ate pizza frequently until it was painful for him. He suffered from reflux and would on occasion vomit (not in a compensatory fashion) due to physical overconsumption. He denied the use of illicit substances and did not smoke. In addition, he reported infrequent alcohol use. His family medical history was unknown.

\section{Baseline testing}

See Table 2 for his baseline weight, BMI, and Yale Food Addiction Scale score. No other self-report measures or scales were administered.

\section{Prescribed protocol}

The patient was seen by Dr. Tro Kalayjian, an internist and obesity medicine physician in his clinic at Yale. The patient indicated that he wanted to try a ketogenic diet for weight loss. Self-reported binge eating was present which met DSM-5 criteria for BED, but was seen in a medicine clinic, thus binge eating was not the focus of the behavioral intervention. Patient was instructed to follow a ketogenic diet similarly described in introduction. Carbohydrates were restricted to under $30 \mathrm{~g}$ per day but protein or fat was not limited. Patient was not asked to count calories. The patient had no other food restrictions. The patient was educated on food quality and hyper-palatability of processed foods and was encouraged to eat unprocessed food. The patient was also encouraged to make ketogenic versions of the foods he enjoyed, for example including pizza crust made from almond flour, protein bars in lieu of processed and refined sugar cookies, and protein chips instead of potato chips. Patient was instructed to include whole foods, fish, eggs, chicken, seafood, low carbohydrate fruits, and a list of non-starchy vegetables and salad. Patient was informed of temporary keto-adaptation side effects as described above in case 1 . Vitals were measured by nursing staff and patient was seen weekly for 16 weeks then as patient directed for follow-up.

\section{Patient outcome}

After following the ketogenic diet for 6 months with no reported major adverse effects (except for temporary fatigue in the first week), the patient's YFAS score was 1; his food addiction symptoms were almost completely resolved. He reported no binge eating episodes and also described a lack of food cravings since initiating the treatment. His reflux symptoms resolved after the first month. After 6 months on the ketogenic diet, he lost $20.4 \mathrm{~kg}$, resulting in a reduction in BMI from $47.1 \mathrm{~kg} / \mathrm{m}^{2}$ (morbid obesity, class 3) to $40.3 \mathrm{~kg} / \mathrm{m}^{2}$ (also morbid obesity, class 3, but close to the BMI cut-off of less than $40 \mathrm{~kg} / \mathrm{m}^{2}$ for class 2 obesity). Thirteen months after initiation of the diet, he reported sustained adherence, with maintained improvements in binge eating and food addiction symptoms. Adherence was measured regularly by dietary recall, tracking of carbohydrates, and by blood ketone measurements showing numbers between $0.5-$ 5.0, indicating nutritional ketosis.

\section{Case presentations: case 3} Baseline interview

A 62-year-old, Caucasian, college-educated female with obesity and self-reported history of binge eating disorder and food addiction symptoms. She also developed hyperlipidemia, hypertension, and a self-diagnosed history of depression. She denied a history of illicit substance use, including nicotine or alcohol. She reported a history of childhood physical and sexual abuse by a step-mother for which she had sought counseling. She reported a lifelong issue controlling her chocolate intake. Reported 
binge frequency was 1-2 times per day with estimated 8-10 times per week. Her family medical history included alcohol abuse, obesity, hypertension, and type 2 diabetes.

\section{Baseline testing}

See Table 2 for her baseline weight, BMI, and Yale Food Addiction Scale score. No other self-report measures or scales were administered. She did meet DSM-5 criteria for binge eating disorder.

\section{Prescribed protocol}

The patient was seen by Dr. Tro Kalayjian. The patient indicated that she wanted to try a ketogenic diet. A ketogenic dietary intervention similar to case 2 was taught. Patient was instructed to include whole foods, fish, eggs, chicken, seafood, low carbohydrate fruits, and a list of non-starchy vegetables and salad. Patient was informed of keto-adaptation side effects as described in case 1 . Vitals were measured by nursing staff and patient was seen weekly for 16 weeks then as patient directed for followup.

At first, a time-restricted eating window of $6 \mathrm{~h}$ was also suggested as a supplement to the dietary intervention, which the patient did not implement until week 6 . It was indicated that she could implement the timerestricted eating window whenever she felt ready, if she even desired to at all. It was encouraged to her to maintain a box of very low-carbohydrate chocolate protein bars in the home and to eat them without restriction. When her food addiction symptoms of cravings and lack of control improved after several months on the ketogenic dietary intervention, the patient then supplemented with a time restricted feeding schedule where food intake was restricted to $6 \mathrm{~h}$ of the day.

\section{Patient outcome}

After following the ketogenic diet for 7 months, she reported no difficulties adhering to the eating protocol and no major adverse events. She initially experienced some headache and fatigue during the first week, which resolved in the second week. She lost $10 \mathrm{~kg}$ over this time period, resulting in a $3.8 \mathrm{~kg} / \mathrm{m}^{2}$ reduction in BMI from $40.4 \mathrm{~kg} / \mathrm{m}^{2}$ (morbid obesity, class 3) to $36.6 \mathrm{~kg} / \mathrm{m}^{2}$ (obesity, class 2). After following the ketogenic diet for 9 months, her YFAS score reduced to 2 indicating a reduction from severe to mild food addiction symptoms. She no longer experienced guilt and felt completely in control of her eating behavior; we observed only 1 binge episode over 9 months. She reported following the ketogenic diet at 6 months after treatment with a total weight loss of $10.9 \mathrm{~kg}$ (13 months after diet initiation). Her BMI and weight at 6 months follow-up were $36.4 \mathrm{~kg} / \mathrm{m}^{2}$ and $99.3 \mathrm{~kg}$, respectively. She stated she frequently eats only one meal a day without experiencing any significant hunger, nor feelings of deprivation, or desire for chocolate. Adherence was measured regularly by dietary recall, tracking of carbohydrates, and by blood ketone measurements showing numbers between $0.5-5.0$, indicating nutritional ketosis.

\section{Discussion and conclusions}

The results of this small case series support the potential feasibility of using a low carbohydrate ketogenic diet for patients presenting with obesity and self-reported binge eating and food addiction symptoms. All patients were able to adhere to the ketogenic diet with no reported major adverse side effects. Patients reported significant reductions in self-reported symptoms of binge eating episodes and food addiction (as measured by YFAS, Y-BOC$\mathrm{BE}$, or reported cravings). Additionally, the patients lost $10-24 \%$ of their body weight. Participants reported maintenance of treatment gains to date of over 9-17 months after initiation of the diet. In addition, when accompanied by co-morbid depressive symptoms, substantial improvements in mood symptoms corresponded with a decline in the PHQ-9.

Ketogenic diets have long been used as an effective treatment for pediatric epilepsy [26]. Randomized clinical trials have shown that a less stringent, low-carbohydrate ketogenic diet, such as the intervention used for these patients, can be effective in treating obesity and reversing type 2 diabetes [27-29]. Ketogenic diets have also been reported to be helpful in other clinical conditions, with case series documenting improvement or resolution of gastro-esophageal reflux disease, irritable bowel syndrome, and Crohn's disease [21, 30-32]. Less is known regarding the effect of ketogenic diets on mental health. Some have observed an improvement in mood in bipolar patients maintained on long-term ketogenic diets, hypothesizing that diet-induced nutritional ketosis mimics the action of mood stabilizers in reducing intracellular sodium and calcium [33]. Others have documented improvement in symptoms of psychosis in patients with schizophrenia $[34,35]$.

The mechanisms by which a low-carbohydrate ketogenic diet influence binge eating and food addiction symptoms are complex, multifactorial, and may involve the effects of nutritional ketosis and its ensuing metabolic effects. Literature review suggests potential mechanisms may involve changes in hormone systems which work to increase satiety, improve leptin sensitivity, and reduce appetite. This may include higher circulating levels of CCK, PYY, and decreases in ghrelin and leptin [36-44]. Other potential mechanisms the literature suggests include changes in metabolism of excitatory amino acids leading to gamma-Aminobutyric acid (GABA) inhibition and brain-derived neurotrophic factor (BDNF) expression [45]. A complete discussion of the literature 
review on potential mechanisms are beyond the scope of this case series paper.

Limitations of this case series should be noted. Without a control condition, it is not possible to distinguish between the effects of dietary restriction generally, versus a low-carbohydrate ketogenic diet specifically, in driving reductions in weight and binge eating symptoms. Nor can we determine, without larger samples, whether the diet's high acceptability among these three patients is typical. Blood ketones were not measured in case 1, but patients were required to complete dietary recalls at follow-ups and report tracking of their total carbohydrates per day. With nutritional ketosis, appetite suppression and satiety are expected effects, thus these symptoms were routinely monitored and obesity medicine physicians clinically distinguish between those in or out of ketosis based on the expected symptomology of ketosis. It is possible that having severe binge eating and food addiction symptoms, which placed these patients into a more impaired subgroup of patients, led them to experience greater benefits than those who were less impaired would have experienced. The relief of experiencing abstinence from cravings may have felt like a worthwhile tradeoff for this group, unlike less symptomatic patients. Additionally, although the Binge Eating Scale (BES) scale has been validated to assess presence of binge eating symptoms, there is no research to show that it can validly diagnose cases of Binge Eating Disorder like the DSM-5 [24]. Finally, as patients were treated by different providers, only the YFAS was uniformly administered to all.

Despite these limitations, we feel this case series demonstrating the feasibility of low carbohydrate ketogenic diets among three individuals with obesity and selfreported binge eating and food addiction symptoms is important, given the lack of prior studies and the importance of understanding the impact of this specific diet for patients with such highly disordered eating.

In summary, research on the role of dietary restriction in the treatment of obesity with co-morbid disordered eating has been limited. We propose that achieving nutritional ketosis through macronutrient dietary restriction of carbohydrates in the treatment of obesity and self-reported binge eating and food addiction symptoms is potentially feasible. Patients experienced reductions in binge eating and food addiction while also losing weight. The findings are limited by the lack of a control group. Although the mechanisms by which sustained ketosis affect appetite and satiety are not definitively understood, they may include hormonemediated impacts. Clinicians may wish to consider a lowcarbohydrate, ketogenic diet for patients with obesity who report binge eating and food addiction symptoms, especially when other interventions have failed. Further research should seek to reproduce the observed effects in controlled trials as well as potential etiologies.

\section{Abbreviations}

BDNF: Brain-derived neurotrophic factor; BED: Binge eating disorder; BES: Binge-eating scale; BMI: Body mass index; CBT: Cognitive behavioral therapy; CCK: Cholecystokinin; GABA: Gamma-Aminobutyric acid; PHQ9: Patient Health Questionnaire; PYY: Polypeptide Y; YBOC-BE: Yale-Brown Obsessive Compulsive Scale modified for Binge Eating; YFAS: Yale Food Addiction Scale

\section{Acknowledgements}

We thank the three patients we reported on in this article and the Obesity Treatment Foundation for their support.

\section{Authors' contributions}

SSD, MC, and DLS drafted the manuscript. SSD and TR led data collection. LRS, AEM, and EW reviewed manuscript drafts. All authors read and approved the final manuscript.

\section{Funding}

This study was not funded. Ashley E. Mason's time was funded by the National Heart, Lung, and Blood Institute (NHLBl; K23HL133442; Mason). Laura Saslow's time was funded by the National Institute of Diabetes and Digestive and Kidney Diseases (NIDDK; K01DK107456; Saslow).

\section{Availability of data and materials}

Data sharing is not applicable to this article as no datasets were generated or analyzed during the current study.

\section{Ethics approval and consent to participate}

As this was a case series, a formal ethics approval was not required. However, this series was approved as a Quality Assurance/Improvement project by the Stanford Department of Psychiatry \& Behavioral Sciences.

\section{Consent for publication}

Written and/or verbal consent has been obtained from all patients.

\section{Competing interests}

Dr. Tro Kalayjian DO discloses spousal ownership of Rosette's baked goods, a low carbohydrate based cookie mixing company and the LowCarbMD podcast. Dr. Eric Westman MD MHS discloses equity in AdaptFor Life and book royalties from Keto Clarity and Cholesterol Clarity. Remaining authors declare that they have no competing interests.

\section{Author details}

${ }^{1}$ The University of Michigan, Ann Arbor, MI, USA. ${ }^{2}$ Department of Psychiatry and Behavioral Sciences, Stanford University School of Medicine, 401 Quarry Road, Stanford, CA 94305 - 5723, USA. ${ }^{3}$ Yale University School of Medicine, New Haven, CT, USA. ${ }^{4}$ The University of California San Francisco, San Francisco, CA, USA. ${ }^{5}$ Duke University School of Medicine, Durham, NC, USA

Received: 9 July 2019 Accepted: 8 January 2020

Published online: 29 January 2020

\section{References}

1. Da Luz F, Hay P, Touyz S, Sainsbury A. Obesity with comorbid eating disorders: associated health risks and treatment approaches. Nutrients. 2018; 10(7):829.

2. Da Luz FQ, Hay P, Gibson AA, Touyz SW, Swinbourne JM, Roekenes JA, Sainsbury A. Does severe dietary energy restriction increase binge eating in overweight or obese individuals? A systematic review. Obes Rev. 2015;16(8): 652-65.

3. Yanovski SZ, Billington CJ, Epstein LH, Goodwin NJ, Hill JO, Pi-Sunyer FX, Rolls BJ, Stern JS, Wadden TA, Weinsier RL, Wilson GT. Dieting and the development of eating disorders in overweight and obese adults. Arch Intern Med. 2000;160(17):2581-9.

4. Polivy J, Herman CP. Dieting and binging: A causal analysis. Am Psychol. 1985:40(2):193.

5. Telch CF, Agras WS. The effects of a very low calorie diet on binge eating Behav Ther. 1993;24(2):177-93.

6. Yanovski SZ, Sebring NG. Recorded food intake of obese women with binge eating disorder before and after weight loss. Int J Eat Disord. 1994; 15(2):135-50. 
7. Raymond NC, de Zwaan M, Mitchell JE, Ackard D, Thuras P. Effect of a very low calorie diet on the diagnostic category of individuals with binge eating disorder. Int J Eat Disord. 2002;31(1):49-56.

8. De Zwaan M, Mitchell JE, Crosby RD, Mussell MP, Raymond NC, Specker SM, Seim HC. Short-term cognitive behavioral treatment does not improve outcome of a comprehensive very-low-calorie diet program in obese women with binge eating disorder. Behav Ther. 2005;36(1):89-99.

9. American Psychiatric Association. Diagnostic and statistical manual of mental disorders (DSM-5 ${ }^{\oplus}$ ). Washington, DC: American Psychiatric Pub; 2013

10. Gearhardt AN, Corbin WR, Brownell KD. Preliminary validation of the Yale food addiction scale. Appetite. 2009;52(2):430-6.

11. Meule A, Gearhardt AN. Five years of the Yale food addiction scale: taking stock and moving forward. Curr Addict Rep. 2014;1(3):193-205.

12. Eichen DM, Lent MR, Goldbacher E, Foster GD. Exploration of "food addiction" in overweight and obese treatment-seeking adults. Appetite. 2013;67:22-4.

13. Burmeister JM, Hinman N, Koball A, Hoffmann DA, Carels RA. Food addiction in adults seeking weight loss treatment. Implications for psychosocial health and weight loss. Appetite. 2013;60:103-10.

14. Lent MR, Eichen DM, Goldbacher E, Wadden TA, Foster GD. Relationship of food addiction to weight loss and attrition during obesity treatment. Obesity. 2014;22(1):52-5.

15. Meule A, Heckel D, Kübler A. Factor structure and item analysis of the Yale food addiction scale in obese candidates for bariatric surgery. Eur Eat Disord Rev. 2012;20(5):419-22.

16. Clark SM, Saules KK. Validation of the Yale food addiction scale among a weight-loss surgery population. Eat Behav. 2013;14(2):216-9.

17. Gearhardt AN, White MA, Masheb RM, Morgan PT, Crosby RD, Grilo CM. An examination of the food addiction construct in obese patients with binge eating disorder. Int J Eat Disord. 2012;45(5):657-63.

18. Gearhardt AN, Corbin WR, Brownell KD. Development of the Yale Food Addiction Scale Version 2.0. Psychol Addict Behav. 2016;30(1):113.

19. Polivy J, Coleman J, Herman CP. The effect of deprivation on food cravings and eating behavior in restrained and unrestrained eaters. Int J Eat Disord. 2005;38(4):301-9.

20. Phinney SD, Volek JS. The art and science of low carbohydrate living: an expert guide to making the life-saving benefits of carbohydrate restriction sustainable and enjoyable. Lexington: Beyond Obesity; 2011.

21. Paoli A, Rubini A, Volek JS, Grimaldi KA. Beyond weight loss: a review of the therapeutic uses of very-low-carbohydrate (ketogenic) diets. Eur J Clin Nutr. 2013;67(8):789.

22. Gibson AA, Seimon RV, Lee CM, Ayre J, Franklin J, Markovic TP, Caterson ID, Sainsbury A. Do ketogenic diets really suppress appetite? A systematic review and meta-analysis. Obes Rev. 2015;16(1):64-76.

23. Löwe B, Unützer J, Callahan CM, Perkins AJ, Kroenke K. Monitoring depression treatment outcomes with the patient health questionnaire-9. Med Care. 2004;1:1194-201.

24. Gormally J, Black S, Daston S, Rardin D. The assessment of binge eating severity among obese persons. Addict Behav. 1982;7(1):47-55.

25. Deal LS, Wirth RJ, Gasior M, Herman BK, McElroy SL. Validation of the YaleBrown obsessive compulsive scale modified for binge eating. Int J Eat Disord. 2015;48(7):994-1004.

26. Swink TD, Vining EP, Freeman JM. The ketogenic diet: 1997. Adv Pediatr. 1997:44:297-329.

27. Sackner-Bernstein J, Kanter D, Kaul S. Dietary intervention for overweight and obese adults: comparison of low-carbohydrate and low-fat diets. A meta-analysis. PLoS One. 2015;10(10):e0139817.

28. Hashimoto Y, Fukuda T, Oyabu C, Tanaka M, Asano M, Yamazaki M, Fukui M. Impact of low-carbohydrate diet on body composition: meta-analysis of randomized controlled studies. Obes Rev. 2016;17(6):499-509.

29. Kirk JK, Graves DE, Craven TE, Lipkin EW, Austin M, Margolis KL. Restrictedcarbohydrate diets in patients with type 2 diabetes: a meta-analysis. J Am Diet Assoc. 2008;108(1):91-100.

30. Austin GL, Thiny MT, Westman EC, Yancy WS, Shaheen NJ. A very lowcarbohydrate diet improves gastroesophageal reflux and its symptoms. Dig Dis Sci. 2006;51(8):1307-12.

31. Austin GL, Dalton CB, Hu Y, Morris CB, Hankins J, Weinland SR, Westman EC Yancy WS Jr, Drossman DA. A very low-carbohydrate diet improves symptoms and quality of life in diarrhea-predominant irritable bowel syndrome. Clin Gastroenterol Hepatol. 2009;7(6):706-8.
32. Olendzki BC, Silverstein TD, Persuitte GM, Ma Y, Baldwin KR, Cave D. An antiinflammatory diet as treatment for inflammatory bowel disease: a case series report. Nutr J. 2014;13(1):5.

33. Phelps JR, Siemers SV, El-Mallakh RS. The ketogenic diet for type II bipolar disorder. Neurocase. 2013;19(5):423-6.

34. Kraft BD, Westman EC. Schizophrenia, gluten, and low-carbohydrate, ketogenic diets: a case report and review of the literature. Nutr Metab. 2009;6(1):10.

35. Pacheco A, Easterling WS, Pryer MW. A pilot study of the ketogenic diet in schizophrenia. Am J Psychiatr. 1965;121(11):1110-1.

36. Klok MD, Jakobsdottir S, Drent ML. The role of leptin and ghrelin in the regulation of food intake and body weight in humans: a review. Obes Rev. 2007;8(1):21-34

37. Stubbs BJ, Cox PJ, Evans RD, Cyranka M, Clarke K, de Wet H. A ketone ester drink lowers human ghrelin and appetite. Obesity. 2018;26(2):269-73.

38. Huda MS, Wilding JP, Pinkney JH. Gut peptides and the regulation of appetite. Obes Rev. 2006;7(2):163-82.

39. Zhao X, Han Q, Gang X, LV Y, Liu Y, Sun C, Wang G. The role of gut hormones in diet-induced weight change: a systematic review. Horm Metab Res. 2017;49(11):816-25

40. Chearskul S, Delbridge E, Shulkes A, Proietto J, Kriketos A. Effect of weight loss and ketosis on postprandial cholecystokinin and free fatty acid concentrations. Am J Clin Nutr. 2008:87(5):1238-46.

41. De Silva A, Bloom SR. Gut hormones and appetite control: a focus on PYY and GLP-1 as therapeutic targets in obesity. Gut Liver. 2012;6(1):10.

42. Hu T, Yao L, Reynolds K, Niu T, Li S, Whelton P, He J, Bazzano L. The effects of a low-carbohydrate diet on appetite: a randomized controlled trial. Nutr Metab Cardiovasc Dis. 2016;26(6):476-88.

43. Considine RV, Sinha MK, Heiman ML, Kriauciunas A, Stephens TW, Nyce MR, Ohannesian JP, Marco CC, McKee LJ, Bauer TL, Caro JF. Serum immunoreactive-leptin concentrations in normal-weight and obese humans. N Engl J Med. 1996;334(5):292-5.

44. Fraser DA, Thoen J, Bondhus S, Haugen M, Reseland JE, Dioseland O, Forre $\mathrm{O}$, Kjeldsen-Kragh J. Reduction in serum leptin and IGF-1 but preserved Tlymphocyte numbers and activation after a ketogenic diet in rheumatoid arthritis patients. Clin Exp Rheumatol. 2000;18(2):209-14.

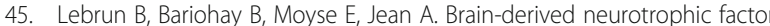
(BDNF) and food intake regulation: a minireview. Auton Neurosci. 2006;126: $30-8$

\section{Publisher's Note}

Springer Nature remains neutral with regard to jurisdictional claims in published maps and institutional affiliations.

Ready to submit your research? Choose BMC and benefit from:

- fast, convenient online submission

- thorough peer review by experienced researchers in your field

- rapid publication on acceptance

- support for research data, including large and complex data types

- gold Open Access which fosters wider collaboration and increased citations

- maximum visibility for your research: over $100 \mathrm{M}$ website views per year

At BMC, research is always in progress.

Learn more biomedcentral.com/submissions 